\title{
Peptide bond formation does not involve acid-base catalysis by ribosomal residues
}

\author{
Peter Bieling ${ }^{1-3}$, Malte Beringer ${ }^{1,3}$, Sarah Adio $^{1,2}$ \& Marina V Rodnina ${ }^{1}$
}

\begin{abstract}
Ribosomes catalyze the formation of peptide bonds between aminoacyl esters of transfer RNAs within a catalytic center composed of ribosomal RNA only. Here we show that the reaction of P-site formylmethionine (fMet)-tRNA ${ }^{\text {fMet }}$ with a modified A-site tRNA substrate, Phelac-tRNA ${ }^{\text {Phe }}$, in which the nucleophilic amino group is replaced with a hydroxyl group, does not show the $\mathrm{pH}$ dependence observed with small substrate analogs such as puromycin and hydroxypuromycin. This indicates that acidbase catalysis by ribosomal residues is not important in the reaction with the full-size substrate. Rather, the ribosome catalyzes peptide bond formation by positioning the tRNAs, or their $3^{\prime}$ termini, through interactions with rRNA that induce and/or stabilize a $\mathrm{pH}$-insensitive conformation of the active site and provide a preorganized environment facilitating the reaction. The rate of peptide bond formation with unmodified Phe-tRNA ${ }^{\text {Phe }}$ is estimated to be $>300 \mathrm{~s}^{-1}$.
\end{abstract}

Ribosomes are two-subunit particles made up of rRNA and proteins. The active site for peptide bond formation, the peptidyl transferase (PT) center, is located on the large ribosomal subunit, 50S. 50S subunits largely depleted of protein retain some PT activity, suggesting that the activity might reside in $23 \mathrm{~S} \mathrm{rRNA}^{1}$. The high-resolution crystal structures of the $50 \mathrm{~S}$ subunit from Haloarcula marismortui have revealed that the PT center is composed of RNA only, with no protein within $15 \AA$ of the active site ${ }^{2,3}$; a similar structure has been observed in 50S subunits from Deinococcus radiodurans ${ }^{4}$. This implies that the PT reaction is catalyzed by RNA and, thus, the ribosome is a ribozyme.

Peptide bond formation is the aminolysis of the ester bond of peptidyl-tRNA (pept-tRNA) in the $\mathrm{P}$ site by aminoacyl-tRNA (aa-tRNA) in the A site (Fig. 1), and there are several ways in which the ribosome may catalyze the reaction. For example, the formation of intermediates and transition states during the reaction may be facilitated at three different steps by abstraction or donation of protons. First, because primary amines in aqueous solution at neutral $\mathrm{pH}$ predominantly exist in the protonated ammonium form, the $\alpha-\mathrm{NH}_{3}^{+}$group of aa-tRNA must be deprotonated to generate the nucleophilic $\mathrm{NH}_{2}$ group. Second, the putative zwitterionic intermediate $\left(\mathrm{T}^{ \pm}\right.$; ref. 5) contains a protonated secondary amine and an oxyanion linked to the tetrahedral carbon. Third, a proton is required to form the leaving group, that is, the $3^{\prime}$ hydroxyl group of deacylated tRNA in the P site. For general acid-base catalysis to occur in an aqueous environment at physiological conditions, the $\mathrm{pK}_{\mathrm{a}}$ values of the catalytic groups have to be close to neutrality to efficiently abstract or donate a proton during the reaction. The $\mathrm{pK}_{\mathrm{a}}$ values of imino protons of the RNA bases are 3.5 for $\mathrm{A}, 4.2$ for $\mathrm{C}$ and 9.2 for
$\mathrm{G}$ and $\mathrm{U}^{6}$, and the $\mathrm{pK}_{\mathrm{a}}$ values of protons at $\mathrm{N} 3$ in $A$ and $\mathrm{G}$ are probably even lower than 3.5 (ref. 7). Thus, if rRNA bases were to take part in chemical catalysis, their $\mathrm{pK}_{\mathrm{a}}$ values would have to be shifted substantially.

In addition to general acid-base catalysis, there are several other ways by which the ribosome may catalyze peptide bond formation. These include orientation and proximity effects and the removal of water from the active site ${ }^{8,9}$. Furthermore, the ribosome may stabilize the transition state by electrostatic interactions and hydrogen bonds; for example, the oxyanion of the $\mathrm{T}^{ \pm}$intermediate is stabilized by water-mediated interactions with $23 \mathrm{~S} \mathrm{rRNA}^{10}$. Finally, the ribosome may work by providing a preorganized electrostatic environment that reduces the activation free energy of the highly polar transition state $^{11,12}$ or may even change the details of the reaction pathway ${ }^{13}$. Several-or all-of the above mechanisms may contribute to the catalysis of peptide bond formation on the ribosome, producing its $4 \times 10^{6}-$ fold acceleration compared to the uncatalyzed reaction ${ }^{14}$.

aa-tRNA, the A-site substrate of the PT reaction, is delivered to the ribosome in a ternary complex with elongation factor $\mathrm{Tu}(\mathrm{EF}-\mathrm{Tu})$ and GTP. Binding of the ternary complex to the ribosome and codon recognition results in GTP hydrolysis by EF-Tu. aa-tRNA is released from EF-Tu-GDP and moves through the ribosome into the PT center (accommodation), where its $3^{\prime}$-terminally aminoacylated CCA end is engaged in multiple interactions with the rRNA ${ }^{15-18}$. aa-tRNA accommodated in the A site of the PT center reacts rapidly with pept-tRNA in the $\mathrm{P}$ site to form pept-tRNA that is one amino acid residue longer in the A site and deacylated tRNA in the P site. Because accommodation is rate-limiting for the PT reaction with aa-tRNA at the conditions tested so far $^{19}$, the catalytic mechanism has not been

${ }^{1}$ Institute of Physical Biochemistry, University of Witten/Herdecke, Stockumer Strasse 10, 58448 Witten, Germany. ${ }^{2}$ Present addresses: EMBL Heidelberg, Meyerhofstrasse 1, 69117 Heidelberg, Germany (P.B.) and Adolf Butenandt Institute, Ludwig Maximilian University, Schillerstrasse 42 , 80336 Munich, Germany (S.A.). ${ }^{3}$ These authors contributed equally to this work. Correspondence should be addressed to M.V.R. (rodnina@uni-wh.de). 


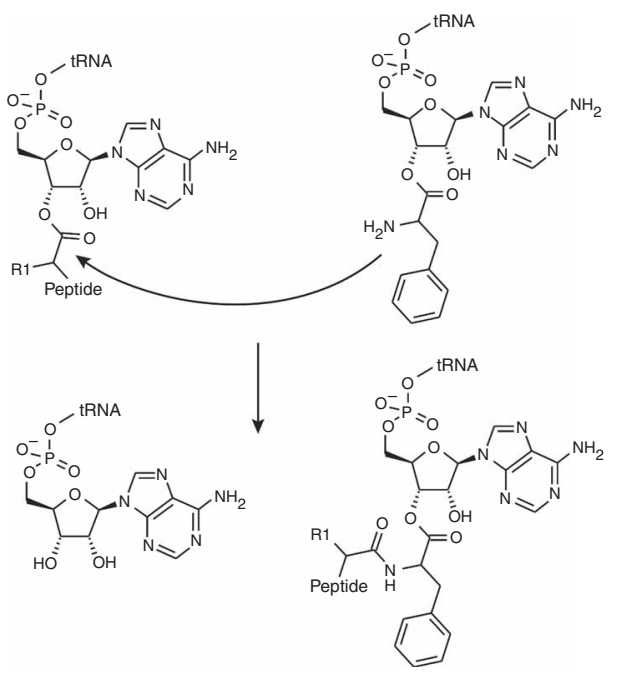

Figure 1 Chemistry of peptide bond formation. 3'ends of the P-site pept-

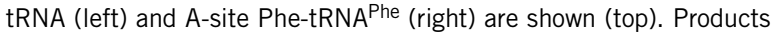
(bottom) are P-site deacylated tRNA (left) and A-site pept-tRNA (right). $\mathrm{R} 1$ denotes the last $\mathrm{C}$-terminal amino acid residue in pept-tRNA.

studied with full-length aa-tRNA. Instead, the small model substrate puromycin (Pmn), mimicking the aminoacylated 3'-terminal adenosine, has been used, as it binds the PT center rapidly compared to the chemistry step ${ }^{14,20}$. However, it is unclear whether the results obtained with such a substrate can be extended to the reaction with full-size aatRNA, because Pmn cannot form most of the tRNA-rRNA interactions $^{21}$. To examine the contribution of general acid-base catalysis to peptide bond formation, we studied the $\mathrm{pH}$ dependence of the PT reaction on ribosomes from Escherichia coli with full-size aatRNA as A-site substrate.

\section{RESULTS}

\section{A-site accommodation and PT reaction of aa-tRNA}

Assuming that an ionizing group on the ribosome with $\mathrm{pK}_{\mathrm{a}}$ in the neutral range is involved in the reaction ${ }^{20}$ and that the $\alpha-\mathrm{NH}_{2}$ group of aa-tRNA has a $\mathrm{pK}_{\mathrm{a}}$ value of 8.0 (ref. 22), the reaction rate between fMet-tRNA $^{\text {fMet }}$ in the P site and Phe-tRNA ${ }^{\text {Phe }}$ in the A site (Fig. 2a) should be strongly $\mathrm{pH}$ dependent. By analogy with the $\mathrm{pH}$ dependence of the reaction using puromycin as Asite substrate ${ }^{20}$, the reaction rate is expected to decrease with $\mathrm{pH}$; at a certain $\mathrm{pH}$, it may become lower than the rate of accommodation, which limits the rate of peptide bond formation at $\mathrm{pH}$ values around neutrality. Provided the accommodation rate is $\mathrm{pH}$ independent, it should then be possible to study the chemistry step in the range below that $\mathrm{pH}$. To test this possibility, we measured rates of aa-tRNA accommodation and peptide bond formation in the $\mathrm{pH}$ range between 6 and 9. Experiments at lower or higher $\mathrm{pH}$ were not possible because of rapid EF-Tu precipitation and tRNA cleavage, respectively.

The rate of aa-tRNA accommodation was measured by fluorescence resonance energy transfer (FRET). fMet-tRNA ${ }^{\mathrm{fMet}}$ was labeled with a fluorescence donor, fluorescein, and different $\mathrm{pHs}$.
Phe-tRNA ${ }^{\text {Phe }}$ with a fluorescence quencher, QSY35. Upon movement of Phe-tRNA ${ }^{\text {Phe }}$ to the A site, the quencher comes into the proximity of the donor, causing a fluorescence decrease. The time course of accommodation was measured by the stopped-flow method (Fig. 2b). The rates of accommodation were identical at $\mathrm{pH}$ values of 6,7 and 8 . The same result was obtained (data not shown) by monitoring the fluorescence of proflavin-labeled Phe-tRNA ${ }^{\text {Phe }}$ (ref. 19).

Rates of peptide bond formation between fMet-tRNA ${ }^{\text {fMet }}$ and Phe-tRNA ${ }^{\text {Phe }}$ were measured by the quench-flow method (Fig. 2c). The observed rate of peptide bond formation was independent of $\mathrm{pH}$ and indistinguishable from the rate of accommodation, about $2-7 \mathrm{~s}^{-1}$ (see below), indicating that the accommodation step was ratelimiting for peptide bond formation over the whole $\mathrm{pH}$ range accessible experimentally. This result may be explained in two ways: either (i) the rate of the PT reaction was not affected by ionization of ribosomal residue(s) or (ii) the chemical step was so fast that the protonation of a group contributing to catalysis did not inhibit peptide bond formation enough to make it slower than accommodation.

\section{Phenyllactyl-tRNA as A-site substrate}

As it was impossible to circumvent or accelerate the accommodation of aa-tRNA, we have used an aminoacyl-tRNA derivative to uncouple the chemistry step from accommodation. The most suitable substrate for this purpose seems to be phenyllactyl-tRNA ${ }^{\text {Phe }}$ (Phelac-tRNA ${ }^{\text {Phe }}$ ), which is identical to the natural substrate Phe-tRNA ${ }^{\text {Phe }}$, except that the nucleophile attacking the ester carbonyl group in pept-tRNA is $\mathrm{OH}$ instead of $\mathrm{NH}_{2}$. 3-phenyllactic acid from Phelac-tRNA ${ }^{\text {Phe }}$ has previously been shown to be incorporated into internal positions of a nascent peptide via an ester linkage ${ }^{23}$. The replacement of $\mathrm{NH}_{2}$ by $\mathrm{OH}$ does not change the catalytic mechanism, as replacing the $\mathrm{NH}_{2}$ group of Pmn with a $\mathrm{OH}$ group $(\mathrm{Pmn}-\mathrm{OH})$ only reduces the rate of the chemistry step without affecting the reaction's $\mathrm{pH}$ dependence ${ }^{24}$ and does not affect the contribution to the reaction of an ionizing group of the ribosome $e^{20}$. Recent ribosomal crystal structures have revealed that hydroxy-derivatives are proper analogs of the substrate and transition state and are positioned in the peptidyl-transferase center in the same way as amino group-containing derivatives ${ }^{10,25}$.

Phelac-tRNA $^{\text {Phe }}$ forms a ternary complex with EF-Tu-GTP, albeit with lower affinity $\left(K_{\mathrm{d}}=30 \mu \mathrm{M}\right)$ than that of Phe-tRNA ${ }^{\text {Phe }}$ $\left(K_{\mathrm{d}}=100 \mathrm{nM}\right)^{26}$. Binding of EF-Tu-GTP-Phelac-tRNA ${ }^{\text {Phe }}$ to the ribosome was complete within $1 \mathrm{~min}$ (data not shown). To examine a

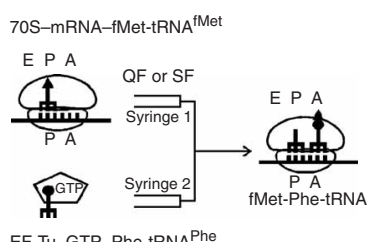

b

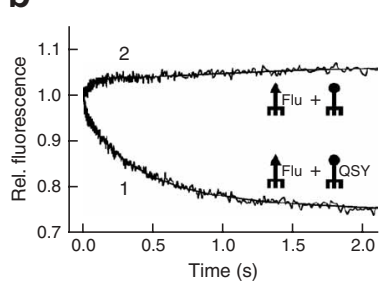

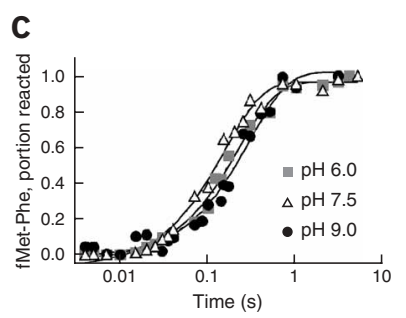

C

Figure 2 Kinetics of accommodation and PT reaction with Phe-tRNA ${ }^{\text {Phe }}$ as substrate. (a) Preparation of ribosome complexes and rapid kinetic PT assay. Ribosomes were programmed with MF-mRNA and contained fMet-tRNA ${ }^{\text {fMet }}$ or fMet-tRNA ${ }^{\text {fMet }}(\mathrm{Flu})$ in the $P$ site. Ternary complex was formed from EF-Tu, GTP and either Phe-tRNA ${ }^{\text {Phe }}$, Phe-tRNA ${ }^{\text {Phe }}(\mathrm{QSY})$ or Phelac-tRNA ${ }^{\text {Phe }}$. Accommodation of aa-tRNA in the A site was measured by stopped flow (SF), the PT reaction by quench flow (QF). (b) Time courses of accommodation (curve 1) upon binding of Phe-tRNA ${ }^{\text {Phe }}(\mathrm{QSY}$ ) to the A site of ribosomes with $\mathrm{FMet}_{\mathrm{TRNA}} \mathrm{A}^{\mathrm{fMet}}(\mathrm{Flu}$ ) in the $\mathrm{P}$ site. Control (curve 2) was carried out with ternary complexes containing unlabeled Phe-tRNA ${ }^{\text {Phe. }}$ (c) Time courses of peptide bond formation at 


\begin{tabular}{|c|c|c|c|c|c|c|c|}
\hline DMS & - & + & + & + & + & + & + \\
\hline Vacant $70 \mathrm{~S}$ & + & + & & & & & \\
\hline 70S-fMet-tRNA ${ }^{\text {fMet }}(P$ site $)$ & & & + & + & & & \\
\hline 70S-tRNA ${ }^{\mathrm{F} M \mathrm{et}}$ (P site) & & & & & + & + & + \\
\hline Phelac-tRNA $^{\text {Phe }}$ (A site) & & & & + & & + & \\
\hline Phe-tRNA ${ }^{\text {Phe }}$ (A site) & & & & & & & + \\
\hline Relative intensity & - & 1.0 & 1.7 & 0.5 & 1.1 & 0.6 & 0.5 \\
\hline
\end{tabular}

whether Phelac-tRNA ${ }^{\text {Phe }}$ is fully accommodated and the $3^{\prime}$ end of tRNA is correctly positioned in the PT center, we probed the interactions between Phelac-tRNA ${ }^{\text {Phe }}$ and $23 \mathrm{~S}$ rRNA by chemical footprinting ${ }^{27}$. Binding of aa-tRNA to the A site leads to protection of several 23S rRNA bases from modification by chemical reagents. Footprints at two bases (A2602 and 42555 ) located directly in the PT center are known to depend on the correct positioning of the amino acid residue at the $3^{\prime}$ end of A site-bound tRNA ${ }^{27}$. If Phelac-tRNA ${ }^{\text {Phe }}$ binds the A site in the same way as unmodified aa-tRNA, these bases in $23 \mathrm{~S}$ rRNA should be protected against chemical modification. Footprinting experiments were carried out with either fMet-tRNA ${ }^{\mathrm{fMet}}$ or deacylated $\mathrm{tRNA}^{\mathrm{fMet}}$ in the $\mathrm{P}$ site (Fig. 3). In the latter case, aa-tRNA in the A site is trapped in the state before peptide bond formation, which allows for proper comparison between the unmodified Phe-tRNA ${ }^{\text {Phe }}$ and Phelac-tRNA ${ }^{\text {Phe }}$, as rapid peptide bond formation between $\mathrm{fMet}^{-\mathrm{tRNA}} \mathrm{fMet}^{\mathrm{fe}}$ and unmodified Phe-tRNA ${ }^{\text {Phe }}$ leads to deprotection of A2602 (ref. 27). In agreement with earlier observations $^{27}$, the reactivity of A2602 toward dimethyl sulfate (DMS) was enhanced when fMet-tRNA ${ }^{\mathrm{fMet}}$ was bound to the P site, whereas with deacylated tRNA ${ }^{\mathrm{fMet}}$ the enhancement was much less (Fig. 3). A-site binding of Phelac-tRNA ${ }^{\text {Phe }}$ led to substantial protection of A2602, similar to that observed with Phe-tRNA ${ }^{\text {Phe }} . \psi 2555$ was protected from 1-cyclohexyl-3-(2-morpholinoethyl) carbodiimide metho-p-toluene sulfate (CMCT) modification to the same extent by Phelac- and

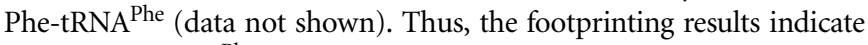
that Phelac-tRNA ${ }^{\text {Phe }}$ accommodates in the active site of the ribosome in a way that is indistinguishable from the positioning of Phe-tRNA ${ }^{\text {Phe }}$. Furthermore, both Phelac-tRNA ${ }^{\text {Phe }}$ binding and the appearance of the specific footprints on $23 \mathrm{~S}$ rRNA (completed within $5 \mathrm{~min}$ ) are much faster than the formation of fMet-Phelac (completed after about $1 \mathrm{~h}$; see below), indicating that, with Phelac-tRNA ${ }^{\text {Phe }}$, the accommodation step is no longer rate limiting for the chemical reaction.

Time courses of ester bond formation between fMet-tRNA ${ }^{\text {fMet }}$ and Phelac-tRNA ${ }^{\text {Phe }}$ on the ribosome showed perfect single-exponential behavior, indicating that only a single active substrate took part in the reaction. The reaction was very slow, about $10^{-3} \mathrm{~s}^{-1}$ (Fig. 4), >50,000 times slower than peptide bond formation with Phe-tRNA ${ }^{\text {Phe }}$ (Fig. 5).

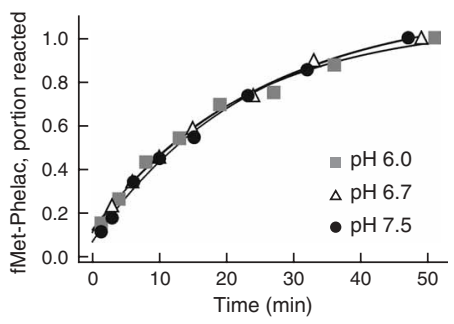

Figure 4 Kinetics of fMet-Phelac formation. Time courses are shown at $\mathrm{pH} 6.0,6.7$ and 7.5.
Figure 3 Correct positioning of Phelac-tRNA ${ }^{\text {Phe }}$ at the PT center. Protection of A2602 in 23S rRNA by tRNA binding was probed by DMS modification. Phe- or Phelac-tRNA ${ }^{\text {Phe }}$ was added as a ternary complex with EF-Tu-GTP. Relative intensities (vacant $70 S=1.0$ ) were calculated from band intensities normalized to control bands within the same lane (not shown in figure); values represent averages from two independent experiments.

The rate constant of $\mathrm{fMet}-\mathrm{Phelac}$ formation was the same at $\mathrm{pH}$ values between 6 and 9 (Figs. 4 and 5). This result constitutes strong evidence against an important contribution of acid-base catalysis and an involvement of ribosomal groups in chemical catalysis of the reaction on the ribosome, at least in the $\mathrm{pH}$ range studied. It is thus possible to estimate a lower limit for the rate constant of peptide bond formation with unmodified aa-tRNA. Taking one ionizing group into account, that is, the $\alpha$-amino group of aa-tRNA, with $\mathrm{pK}_{\mathrm{a}}=$ 8.0 and a measured rate of peptidyl transfer $\left(k_{\text {pep }}\right)$ of $5 \mathrm{~s}^{-1}$ at $\mathrm{pH} 6.5$, the lower limit for the rate of the chemistry step would be $>300 \mathrm{~s}^{-1}$ for $\mathrm{pH}>8.5$ (Fig. 5), more than six times faster than the rate measured with puromycin ${ }^{20}$.

\section{DISCUSSION}

The present data show that catalysis of the reaction of P-site fMettRNA $^{\text {fMet }}$ with the modified A-site substrate, Phelac-tRNA ${ }^{\text {Phe }}$, does not involve ribosomal groups ionizing at neutral $\mathrm{pH}$, indicating that the contribution of general acid-base catalysis is small. The mechanism of ester aminolysis is similar but not identical to peptide bond formation. Nevertheless, the observed $\mathrm{pH}$ independence of the reaction with Phelac-tRNA cannot be due to the $\mathrm{NH}_{2}$-to-OH replacement, because the reaction with $\mathrm{Pmn}-\mathrm{OH}$ shows the same $\mathrm{pH}$ dependence as that with Pmn, except for the absence of the effect of protonation of the nucleophilic $\mathrm{NH}_{2}$ group. The absence of $\mathrm{pH}$ dependence between $\mathrm{pH} 6$ and 9 does not by itself rule out acidbase catalysis, because the combination of an acid and a base with $\mathrm{pK}_{\mathrm{a}}$ values outside this range may produce the same effect. In such a case, the observed $\mathrm{pH}$ independence is not due to the absence of deprotonation-protonation events, but instead is due to the decreased abundance of the functional form of the acid being offset by the increased abundance of the functional form of the base $\mathrm{e}^{28}$. In fact, there are examples of ribozymes using acid-base catalysis by nucleobases with $\mathrm{pK}_{\mathrm{a}} \mathrm{s}$ outside the neutral range ${ }^{6,29}$. Notably, the reaction rates achieved by such catalysts are very moderate, usually $<1 \mathrm{~min}^{-1}$, for the following reason. Assuming $\mathrm{p} K_{\mathrm{a}}$ values of the catalytic acid and base just outside the 6-9 range, for example, $\mathrm{pK}_{\mathrm{a}}=5$ and 10 , respectively, the activity of such an enzyme at neutral $\mathrm{pH}$ (calculated

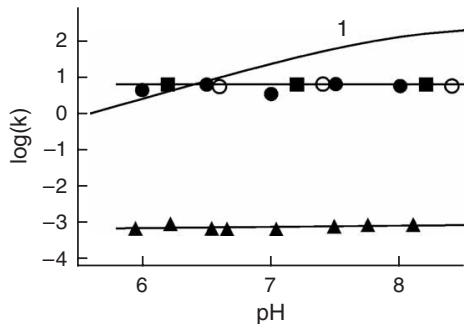

Figure 5 Summary of rate constants. Shown is $\mathrm{pH}$ dependence of rate constants for accommodation ( $\boldsymbol{\square}$ ) and for peptidyl-transfer reactions with Phe-tRNA ${ }^{\text {Phe }}(\bullet)$, Phelac-tRNA ${ }^{\text {Phe }}(\mathbf{\Delta})$ and Phe-tRNAPhe treated with nitrous acid before aminoacylation $(O)$ as A-site substrates. Curve 1 is a model for the $\mathrm{pH}$ dependence of peptide bond formation with Phe-tRNAPhe, calculated assuming one ionizing group ( $\mathrm{pK}_{\mathrm{al}}=8.0$ for the $\alpha$-amino group of aa-tRNA) and a measured $k_{\text {pep }}=5 \mathrm{~s}^{-1}$ at $\mathrm{pH}=6.5$. 
as in ref. 28) is five orders of magnitude lower than the maximum rate $\left(k_{\max }\right)$ for a bond-forming or bond-breaking event. Furthermore, $k_{\max }$ itself is a function of the Brønsted coefficient $\left(\beta_{\text {nuc }}\right)$. In most ribozymes, this value is about 0.5 (ref. 28), but it seems to be very low $\left(\beta_{\text {nuc }}<0.2\right)$ on the ribosome ${ }^{30}$, suggesting that the positive charge on the nitrogen in the transition state is very small. Thus, models assuming active acid-base catalysis by groups ionizing far outside the neutral $\mathrm{pH}$ range are inconsistent with the high rate of peptide bond formation on the ribosome.

The 3'-terminal CCA sequence of A-site tRNA interacts with residues of $23 \mathrm{~S}$ rRNA in the active site. Recent crystal structures have shown that proper binding of CC-hPmn, an A-site substrate analog containing hydroxypuromycin attached to a CC dinucleotide, induces specific movements of rRNA residues in the PT center, thereby reorienting the ester group of peptidyl-tRNA and making it accessible for attack ${ }^{25}$. These interactions, as well as other contacts of the tRNA body with the ribosome ${ }^{16}$, may stabilize the structure of the PT center in its active conformation. They accelerate the reaction $\left(k_{\text {pep }}>300 \mathrm{~s}^{-1}\right.$ with Phe-tRNA ${ }^{\text {Phe }}$ compared to $50 \mathrm{~s}^{-1}$ for $\mathrm{Pmn}$ ) and abolish its dependence on $\mathrm{pH}$, suggesting a contribution of tRNA interactions with the ribosome to the catalysis of peptidebond formation.

Unlike aa-tRNA, Pmn and Pmn-OH show a strong $\mathrm{pH}$ dependence of the rate of the PT reaction. Deprotonation of a ribosomal group with a $\mathrm{pK}_{\mathrm{a}}$ value of 7.5 increases the rate of the reaction $\sim 150$-fold ${ }^{20,21}$. This effect indicates either chemical catalysis involving an ionizing group of the ribosome or a $\mathrm{pH}$-dependent conformational change in the active site that affects the rate of the reaction. Pmn is not positioned by interactions with $23 \mathrm{~S}$ rRNA, which may render the PT reaction with $\mathrm{Pmn}$ more sensitive to $\mathrm{pH}$-dependent structural rearrangements. In fact, the structure of the ribosome is known to be sensitive to $\mathrm{pH}$ changes ${ }^{7,31-33}$, and the conformation induced by increasing the $\mathrm{pH}$ may have higher activity in the peptidyl-transfer reaction. Apparently, the $\mathrm{pH}$-dependent activation cannot occur when a full-size tRNA is bound to the A site; consequently, the rates of reaction with $\mathrm{Pmn}-\mathrm{OH}$ and Phelac, which are similar at low $\mathrm{pH}$ values, become quite different at high $\mathrm{pH}$. The addition of a single cytidine residue to Pmn is sufficient to abolish the strong $\mathrm{pH}$ dependence of catalysis $^{34}$. Mutations of a number of rRNA residues within the PT center have no effect on the rate of peptide bond formation with aa-tRNA as A-site substrate, whereas the reaction with Pmn is strongly inhibited ${ }^{20,21,35}$. This again indicates that the reaction with aa-tRNA is robust: it is not affected by base changes within the active site, probably because of substrate-induced stabilization of the active conformation. In contrast, the reaction with Pmn seems to be sensitive to structural changes induced by mutations in $23 \mathrm{~S} \mathrm{rRNA}^{35,36}$.

The $2^{\prime} \mathrm{OH}$ of A76 of the P-site tRNA has been suggested to have an important role in catalysis ${ }^{37}$. Substitution of this $2^{\prime} \mathrm{OH}$ by $2^{\prime} \mathrm{H}$ or $2^{\prime} \mathrm{F}$ greatly reduces the rate of peptide bond formation, leading to the proposal that peptide bond formation is promoted by substrateassisted catalysis, with the $2^{\prime} \mathrm{OH}$ of A76 acting as a general acid or base $\mathrm{s}^{37}$. Measurements with model substrates in the absence of ribosomes have shown that the presence or absence of a hydroxyl group in the substrate has only small effects on catalysis, suggesting that the $2^{\prime} \mathrm{OH}$ of the P-site tRNA may be important in the context of the ribosome only ${ }^{11}$. The present results- $\mathrm{pH}$ independence of peptide bond formation with full-size tRNA substrates-show that even if the $2^{\prime} \mathrm{OH}$ is involved in proton transfer, its $\mathrm{pK}_{\mathrm{a}}$ is not shifted to the neutral $\mathrm{pH}$ range, in agreement with recent crystal structures ${ }^{10}$. Instead, the position and conformation of the $2^{\prime} \mathrm{OH}$ may be crucial for supporting a network of hydrogen bonds and electrostatic interactions that stabilize the transition state ${ }^{10-12}$.

Our data suggest there is a very small contribution, if any, of chemical catalysis to peptide bond formation on the ribosome, consistent with ribosome mutagenesis data that provide evidence against a catalytic role of active site nucleotides ${ }^{21}$. Furthermore, our data strongly support a recently proposed mechanism that does not involve general acid-base catalysis by ribosomal groups, but an intrareactant proton shuttling via the P-site adenosine $2^{\prime}$ oxygen, after the attack of the A-site $\alpha$-amino group on the $\mathrm{P}$-site ester ${ }^{10,12,38}$. Most of the catalytic power of the ribosome seems to result from tight binding of tRNA substrates in the active site through interactions of their $3^{\prime}$ ends with $23 \mathrm{~S}$ rRNA. In addition to putting the reactive groups in close proximity and a precise orientation relative to each other, the ribosome may work by providing a preorganized electrostatic environment that reduces the activation energy of the highly polar transition state, by shielding the reaction against bulk water, by helping the proton shuttle form the leaving group or by a combination of these effects ${ }^{10-12,14,25}$.

The ribosome is an ancient RNA catalyst that accelerates the PT reaction by a factor of $4 \times 10^{6}$ (ref. 14). It is much less efficient than protein enzymes that use chemical catalysis and accelerate reactions by up to $10^{23}$-fold ${ }^{39}$. Apparently, evolutionary pressure has had a much larger influence on the speed and fidelity of the ratelimiting steps of protein synthesis that do not involve chemistry, such as substrate binding ${ }^{40}$, than on the chemistry step of peptide bond formation. This has allowed the ribosome to retain its catalytic strategy during the evolution of a prebiotic translational ribozyme into a modern ribosome. Thus, the catalytic mechanism used by the ribosome seems to represent a fossil of a primitive catalyst from the RNA world.

\section{METHODS}

Standard materials. Experiments were carried out in buffer A (50 mM Tris$\mathrm{HCl}(\mathrm{pH} 7.5), 70 \mathrm{mM} \mathrm{NH}_{4} \mathrm{Cl}, 30 \mathrm{mM} \mathrm{KCl}$ and $7 \mathrm{mM} \mathrm{MgCl}_{2}$ ) at $37{ }^{\circ} \mathrm{C}$. Ribosomes from E. coli MRE600, initiation factors, EF-Tu, f $\left[{ }^{3} \mathrm{H}\right]$ Met-tRNA ${ }^{\mathrm{fMet}}$, $\left[{ }^{14} \mathrm{C}\right]$ Phe-tRNA ${ }^{\text {Phe }}$ and MF-mRNA (coding for fMet-Phe) were prepared as described in refs. 19,41,42. Fluorescence labeling of tRNA ${ }^{\text {fMet }}$ and $t R N A^{\text {Phe }}$ at 4-thioU(8) with fluorescein (Flu) and QSY35 (QSY), respectively, was carried out as described in ref. 43. $\mathrm{f}\left[{ }^{3} \mathrm{H}\right]$ Met-tRNA ${ }^{\mathrm{fMet}}(\mathrm{Flu})$ and $\left[{ }^{14} \mathrm{C}\right] \mathrm{Phe}-$ tRNA $^{\text {Phe }}(\mathrm{QSY})$ were purified by HPLC on a Hibar $250 \mathrm{RP}-18(5 \mu \mathrm{m})$ column (Merck) using a $0 \%-15 \%(\mathrm{v} / \mathrm{v})$ gradient of ethanol in $20 \mathrm{mM}$ ammonium acetate (pH 5), $10 \mathrm{mM} \mathrm{MgCl} 2$ and $400 \mathrm{mM} \mathrm{NaCl}$.

Preparation of Phelac-tRNA ${ }^{\text {Phe }} \cdot\left[{ }^{14} \mathrm{C}\right]$ Phelac-tRNA ${ }^{\text {Phe }}$ was prepared by deamination of $\left[{ }^{14} \mathrm{C}\right]$ Phe-tRNA ${ }^{\text {Phe }}$ by treatment with nitrous acid ${ }^{26,44}$. The major products of deamination of Phe-tRNA ${ }^{\text {Phe }}$ are the 3-phenyllactic-tRNA ${ }^{\text {Phe }}$ (present as a mixture of $\mathrm{L}_{-}$and $\mathrm{D}$-isomers) and cinnamyl-tRNA ${ }^{\mathrm{Ph}} \cdot\left[{ }^{14} \mathrm{C}\right]$ PhelactRNA $^{\text {Phe }}$ was purified by HPLC as described above. Phelac-tRNA ${ }^{\text {Phe }}$ eluted as a major peak at $11.5 \%(\mathrm{v} / \mathrm{v})$ ethanol. For product analysis before and after HPLC purification, an aliquot containing 120 pmol $\left[{ }^{14} \mathrm{C}\right]$ Phelac-tRNA was hydrolyzed by incubation in $\mathrm{KOH}(0.5 \mathrm{M})$ for $30 \mathrm{~min}$. After neutralization with glacial acetic acid $(10 \%(\mathrm{v} / \mathrm{v}))$, the products were separated by analytical HPLC on a LiChrosPher RP-18 $(7 \mu \mathrm{M})$ column (Merck) using an adapted $0 \%-50 \%(\mathrm{v} / \mathrm{v})$ gradient of acetonitril in $0.1 \%(\mathrm{v} / \mathrm{v})$ trifluoroacetic acid. Fractions were analyzed by radioactivity counting in Lumasafe Plus (Packard). For product identification by retention times, phenyllactic acid (retention time $9 \mathrm{~min})$, phenylalanine $(6 \mathrm{~min})$ and cinnamic acid $(13 \mathrm{~min})$ were used as references; reference substances were detected by monitoring optical density at $210 \mathrm{~nm}$. Hydrolysates of HPLC-purified $\left[{ }^{14} \mathrm{C}\right]$ Phelac-tRNA ${ }^{\text {Phe }}$ eluted as a sharp peak exclusively at the position of phenyllactic acid $(9 \mathrm{~min})$. To analyze the content of $\mathrm{D}$ - and $\mathrm{L}$-stereoisomers in the preparation, $\left[{ }^{14} \mathrm{C}\right]$ Phelac-tRNA ${ }^{\text {Phe }}$ was hydrolyzed in $200 \mathrm{mM}$ ammonium carbonate for $45 \mathrm{~min}$ at $45^{\circ} \mathrm{C}$, and $\left[{ }^{14} \mathrm{C}\right]$ Phelac was separated from tRNA on a NICK column (Amersham) 
and dried. The powder was dissolved in $200 \mu \mathrm{l}$ of buffer ( $1 \mathrm{mM}$ copper (II) acetate, $50 \mathrm{mM}$ ammonium acetate and $7.5 \%(\mathrm{v} / \mathrm{v})$ acetonitril ( $\mathrm{pH} 5.0)$ ) in the presence of $\mathrm{L}-$ and D-phenyllactic acid standards (Sigma) and analyzed by isocratic runs on a Chirex 3126 (Phenomenex) column. $\left[{ }^{14} \mathrm{C}\right] \mathrm{Phelac}-\mathrm{TRNA}^{\mathrm{Phe}}$ preparations contained $20 \%$ L- and $80 \%$ D-isomer. Separation of stereoisomers of $\left[{ }^{14} \mathrm{C}\right]$ Phelac-tRNA ${ }^{\text {Phe }}$ was not possible and was not undertaken, because the $\mathrm{D}$-isomers are inactive as A-site substrates (see below). To test whether incubation with nitrous acid modified the properties of tRNA, deacylated $\mathrm{TRNA}^{\text {Phe }}$ was treated as described above, purified, aminoacylated with $\left[{ }^{14} \mathrm{C}\right] \mathrm{Phe}$ and tested in ribosome binding and peptide bond formation. The rate of peptide bond formation with nitrous acid-treated PhetRNA $^{\text {Phe }}$ was identical to that measured with untreated tRNA, $5 \mathrm{~s}^{-1}$ (Fig. 5), indicating that the tRNA remained fully functional when attached to the unmodified amino acid.

Synthesis of fMet-Phe and fMet-Phelac. Initiation complexes were prepared by incubating 70 S ribosomes $(1 \mu \mathrm{M})$ with a 1.2 -fold excess of MF-mRNA, $1.5 \mu \mathrm{M}$ each of initiation factors IF1, IF2 and IF3, $1.5 \mu \mathrm{M} \mathrm{f}\left[{ }^{3} \mathrm{H}\right] \mathrm{Met}^{-t R N A}{ }^{\mathrm{fMet}}$ and $1 \mathrm{mM}$ GTP in buffer A for $1 \mathrm{~h}$ at $37{ }^{\circ} \mathrm{C}$. Complexes were purified and concentrated by centrifugation through $400-\mu$ l sucrose cushions (1.1 M sucrose in buffer A) at 260,000g for $2 \mathrm{~h}$ (RC M120 GX, Sorvall). Ribosome pellets were dissolved in buffer A to a final concentration of $7 \mu \mathrm{M}$, shock-frozen in liquid nitrogen and stored at $-80^{\circ} \mathrm{C}$. Ribosome complexes with deacylated tRNA ${ }^{\mathrm{fMet}}$ in the P site were prepared by treating initiation complexes $(1 \mu \mathrm{M})$ with Pmn $(10 \mathrm{mM})$ in buffer A for $15 \mathrm{~min}$ at $37^{\circ} \mathrm{C}$. Complexes were purified and concentrated by ultracentrifugation as above. Both types of complexes, with deacylated or fMet-tRNA ${ }^{\mathrm{fMet}}$ in the P site, were $>90 \%$ active in binding of $\left[{ }^{14} \mathrm{C}\right]$ Phe-tRNA ${ }^{\text {Phe }}$, according to nitrocellulose-filtration results. Ternary complexes (EF-Tu-GTP- $\left[{ }^{14} \mathrm{C}\right]$ Phe-tRNA ${ }^{\text {Phe }}$ ) were prepared by incubating EF-Tu $(48 \mu \mathrm{M})$ with GTP $(1 \mathrm{mM})$, phosphoenol pyruvate $(3 \mathrm{mM})$ and pyruvate kinase $\left(0.1 \mathrm{mg} \mathrm{l}^{-1}\right)$ for $15 \mathrm{~min}$ at $37{ }^{\circ} \mathrm{C}$, then adding $\left[{ }^{14} \mathrm{C}\right]$ Phe-tRNA ${ }^{\text {Phe }}$ or $\left[{ }^{14} \mathrm{C}\right]$ Phe-tRNA ${ }^{\text {Phe }}(\mathrm{QSY})(12 \mu \mathrm{M})$. The ternary complex with Phelac-tRNA ${ }^{\text {Phe }}$ was prepared in the same way, except for the use of a higher concentration of EF-Tu (20-fold excess over tRNA).

Reactions of ribosome complex $(1 \mu \mathrm{M})$ and EF-Tu-GTP- $\left[{ }^{14} \mathrm{C}\right]$ Phelac$\operatorname{tRNA}^{\text {Phe }}(1.5 \mu \mathrm{M})$ were stopped by the addition of $25 \%(\mathrm{v} / \mathrm{v})$ formic acid and $f\left[{ }^{3} \mathrm{H}\right]$ Met- $\left[{ }^{14} \mathrm{C}\right]$ Phelac-tRNA was pelleted by centrifugation. Pellets were dissolved in $40 \mu \mathrm{l}$ of buffer B $(50 \mathrm{mM}$ Tris- $\mathrm{HCl}, 20 \mathrm{mM}$ Bis-Tris, $70 \mathrm{mM}$ $\mathrm{NH}_{4} \mathrm{Cl}, 30 \mathrm{mM} \mathrm{KCl}$ and $7 \mathrm{mM} \mathrm{MgCl}_{2}$ (pH 6.2)) and the $\mathrm{pH}$ was adjusted to 6.5 with $1 \mathrm{M} \mathrm{KOH}$. RNase A $\left(2 \mathrm{mg} \mathrm{ml}^{-1}\right)$ was added in the same buffer and digestion was carried out at $37^{\circ} \mathrm{C}$ for $30 \mathrm{~min}$, followed by centrifugation. After dilution of the supernatant to a total volume of $200 \mu \mathrm{l}$ with $0.1 \%(\mathrm{v} / \mathrm{v})$ trifluoroacetic acid, the reaction products were analyzed by reverse-phase HPLC as described above. The presumed fMet-Phelac reaction product was clearly separated from both fMet and Phelac fractions and contained $\left[{ }^{3} \mathrm{H}\right] \mathrm{Met}$ and $\left[{ }^{14} \mathrm{C}\right]$ Phelac in strictly stoichiometric amounts. The presence of the ester bond was verified by alkaline hydrolysis (in $0.5 \mathrm{M} \mathrm{KOH}$ for $30 \mathrm{~min}$ at $37{ }^{\circ} \mathrm{C}$ ). This resulted in complete hydrolysis of fMet-Phelac to fMet and Phelac, whereas no hydrolysis of the dipeptide fMet-Phe was found under these conditions. The yield of fMet-Phelac was $\sim 30 \%$ per ribosome at all $\mathrm{pH}$ values (normalized to the maximum portion reacted in Fig. 4). This corresponded to the portion of L-Phelac-tRNA ${ }^{\text {Phe }}$ included $\left(20 \%\right.$ in Phelac-tRNA ${ }^{\text {Phe }}$ preparations that were added in 1.5 -fold excess over the ribosomes), which was bound to the ribosome in preference over the D-isomer. To determine the ratio of $\mathrm{L}-$ and D-isomers of Phelac in the product, $\mathrm{f}\left[{ }^{3} \mathrm{H}\right]$ Met- $\left[{ }^{14} \mathrm{C}\right]$ Phelac-tRNA ${ }^{\text {Phe }}$ was separated from ribosomes by ultracentrifugation, purified from $\mathrm{f}\left[{ }^{3} \mathrm{H}\right]$ MettRNA ${ }^{\mathrm{fMet}}$ and $\left[{ }^{14} \mathrm{C}\right]$ Phelac-tRNA ${ }^{\text {Phe }}$ by HPLC on a Hibar $250 \mathrm{RP}-18(5 \mu \mathrm{m})$ column as described above and dried. fMet-Phelac was hydrolyzed by ammonium carbonate for $45 \mathrm{~min}$ at $45{ }^{\circ} \mathrm{C}$ and treated exactly as described above for Phelac. HPLC analysis on a Chirex 3126 (Phenomenex) column and radioactivity counting revealed that all the $\left[{ }^{14} \mathrm{C}\right] \mathrm{Phelac}$ in the product was the $\mathrm{L}$-isomer.

Chemical modification. Chemical modification experiments were carried out as described in ref. 45 after mixing $1 \mu \mathrm{M}$ initiation complex with $1.5 \mu \mathrm{M}$ ternary complex. Incubation with DMS or CMCT was for $8 \mathrm{~min}$ at $37{ }^{\circ} \mathrm{C}$. Modification of residues at the PT center was monitored by reverse transcriptase sequencing using a ${ }^{32} \mathrm{P} 5^{\prime}$ end-labeled DNA primer, 5'-GGTCCTCTGTACTAGGAGC-3', complementary to E. coli $23 \mathrm{~S}$ rRNA nucleotides 2667-2648.

Kinetic assays. For kinetic assays, ribosome and ternary complex stocks were diluted 1:10 into the desired buffer, and the $\mathrm{pH}$ of both solutions was measured using a small-size $\mathrm{pH}$ electrode. Fluorescence stopped-flow measurements were performed and the data evaluated as described previously ${ }^{19}$. Fluorescein fluorescence was excited at $470 \mathrm{~nm}$ and measured after passing a KV500 cutoff filter (Schott). Experiments were performed in buffer B at desired $\mathrm{pH}$ and at $37^{\circ} \mathrm{C}$ by rapidly mixing equal volumes $(55 \mu \mathrm{l})$ each of the ribosome complex $(0.4 \mu \mathrm{M})$ and ternary complex $(1.2 \mu \mathrm{M})$. Time courses were evaluated by a function with three exponential terms. The first two exponential terms were necessary to describe a small, rapid fluorescence decrease, which most likely represents (i) the initial binding of the ternary complex to the ribosome, and (ii) codon recognition (H.-J. Wieden and M.V.R., unpublished data). The third exponential term, accounting for $>80 \%$ of the fluorescence decrease, reflects the accommodation of tRNA in the A site.

Quench-flow assays were performed at $37{ }^{\circ} \mathrm{C}$ in a KinTek apparatus, mixing equal volumes $(12 \mu \mathrm{l})$ each of ribosome $(0.4 \mu \mathrm{M})$ and ternary complex $(1.2 \mu \mathrm{M})$ solution. Reactions with Phe-tRNA ${ }^{\text {Phe }}$ were quenched with $\mathrm{KOH}$ $(0.5 \mathrm{M}), \mathrm{f}\left[{ }^{3} \mathrm{H}\right]$ Met- $\left[{ }^{14} \mathrm{C}\right]$ Phe formed by the PT reaction was set free from $\mathrm{f}\left[{ }^{3} \mathrm{H}\right]$ Met- $\left[{ }^{14} \mathrm{C}\right]$ Phe-tRNA ${ }^{\text {Phe }}$ by alkaline hydrolysis $\left(30 \mathrm{~min}\right.$ at $\left.37^{\circ} \mathrm{C}\right)$ and unreacted $\mathrm{f}\left[{ }^{3} \mathrm{H}\right]$ Met and $\left[{ }^{14} \mathrm{C}\right]$ Phe were separated by reverse-phase HPLC and quantitated by double-label radioactivity counting ${ }^{20}$.

\section{ACKNOWLEDGMENTS}

We thank W. Wintermeyer for discussion and valuable comments on the manuscript, H.-J. Wieden for fMet-tRNA ${ }^{\mathrm{fMet}}(\mathrm{Flu})$ and Phe-tRNA ${ }^{\mathrm{Phe}}(\mathrm{QSY})$, Y.P. Semenkov and V.I. Katunin (Petersburg Nuclear Physics Institute) for generous gifts of tRNAs, D. Rodnin for ribosome preparations and A. Böhm, P. Striebeck, C. Schillings and S. Möbitz for expert technical assistance. The work was supported by the Deutsche Forschungsgemeinschaft, the European Union, the Alfried Krupp von Bohlen und Halbach-Stiftung and the Fonds der Chemischen Industrie.

\section{COMPETING INTERESTS STATEMENT}

The authors declare that they have no competing financial interests.

Published online at http://www.nature.com/nsmb/

Reprints and permissions information is available online at http://npg.nature.com/ reprintsandpermissions/

1. Noller, H.F., Hoffarth, V. \& Zimniak, L. Unusual resistance of peptidyl transferase to protein extraction procedures. Science 256, 1416-1419 (1992).

2. Ban, N., Nissen, P., Hansen, J., Moore, P.B. \& Steitz, T.A. The complete atomic structure of the large ribosomal subunit at $2.4 \AA$ resolution. Science 289, 905-920 (2000).

3. Nissen, P., Hansen, J., Ban, N., Moore, P.B. \& Steitz, T.A. The structural basis of ribosome activity in peptide bond synthesis. Science 289, 920-930 (2000)

4. Harms, J. et al. High resolution structure of the large ribosomal subunit from a mesophilic eubacterium. Cel/ 107, 679-688 (2001).

5. Satterthwait, A.C. \& Jencks, W.P. The mechanism of the aminolysis of acetate esters. J. Am. Chem. Soc. 96, 7018-7031 (1974).

6. Bevilacqua, P.C., Brown, T.S., Nakano, S. \& Yajima, R. Catalytic roles for proton transfer and protonation in ribozymes. Biopolymers 73, 90-109 (2004).

7. Muth, G.W., Chen, L., Kosek, A.B. \& Strobel, S.A. pH-dependent conformational flexibility within the ribosomal peptidyl transferase center. RNA 7, 1403-1415 (2001).

8. Krayevsky, A.A. \& Kukhanova, M.K. The peptidyltransferase center of ribosomes. Prog. Nucleic Acid Res. Mol. Biol. 23, 1-51 (1979).

9. Nierhaus, K.H., Schulze, H. \& Cooperman, B.S. Molecular mechanisms of the ribosomal peptidyltransferase center. Biochem. Int. 1, 185-192 (1980).

10. Schmeing, T.M., Huang, K.S., Kitchen, D.E., Strobel, S.A. \& Steitz, T.A. Structural insights into the roles of water and the 2 ' hydroxyl of the P site tRNA in the peptidyl transferase reaction. Mol. Cel/ 20, 437-448 (2005).

11. Sharma, P.K., Xiang, Y., Kato, M. \& Warshel, A. What are the roles of substrateassisted catalysis and proximity effects in peptide bond formation by the ribosome? Biochemistry 44, 11307-11314 (2005).

12. Trobro, S. \& Aqvist, J. Mechanism of peptide bond synthesis on the ribosome. Proc. Natl. Acad. Sci. USA 102, 12395-12400 (2005).

13. Seila, A.C., Okuda, K., Nunez, S., Seila, A.F. \& Strobel, S.A. Kinetic isotope effect analysis of the ribosomal peptidyl transferase reaction. Biochemistry 44, 4018-4027 (2005).

14. Sievers, A., Beringer, M., Rodnina, M.V. \& Wolfenden, R. The ribosome as an entropy trap. Proc. Natl. Acad. Sci. USA 101, 7897-7901 (2004). 
15. Hansen, J.L., Schmeing, T.M., Moore, P.B. \& Steitz, T.A. Structural insights into peptide bond formation. Proc. Natl. Acad. Sci. USA 99, 11670-11675 (2002).

16. Yusupov, M.M. et al. Crystal structure of the ribosome at $5.5 \AA$ resolution. Science 292, 883-896 (2001).

17. Bashan, A. et al. Structural basis of the ribosomal machinery for peptide bond formation, translocation, and nascent chain progression. Mol. Cell 11, 91-102 (2003).

18. Kim, D.F. \& Green, R. Base-pairing between 23S rRNA and tRNA in the ribosomal A site. Mol. Cell 4, 859-864 (1999).

19. Pape, T., Wintermeyer, W. \& Rodnina, M.V. Complete kinetic mechanism of elongation factor Tu-dependent binding of aminoacyl-tRNA to the A site of the E.coli ribosome. EMBO J. 17, 7490-7497 (1998).

20. Katunin, V.I. Muth, G.W. Strobel, S.A., Wintermeyer, W. \& Rodnina, M.V. Important contribution to catalysis of peptide bond formation by a single ionizing group within the ribosome. Mol. Cell 10, 339-346 (2002).

21. Youngman, E.M., Brunelle, J.L., Kochaniak, A.B. \& Green, R. The active site of the ribosome is composed of two layers of conserved nucleotides with distinct roles in peptide bond formation and peptide release. Cell 117, 589-599 (2004).

22. Wolfenden, R. The mechanism of hydrolysis of amino acyl RNA. Biochemistry $\mathbf{3 3 8}$, 1090-1092 (1963).

23. Fahnestock, S. \& Rich, A. Synthesis by ribosomes of viral coat protein containing ester linkages. Nat. New Biol. 229, 8-10 (1971).

24. Fahnestock, S., Neumann, H., Shashoua, V. \& Rich, A. Ribosome-catalyzed ester formation. Biochemistry 9, 2477-2483 (1970).

25. Schmeing, T.M., Huang, K.S., Strobel, S.A. \& Steitz, T.A. An induced-fit mechanism to promote peptide bond formation and exclude hydrolysis of peptidyl-tRNA. Nature 438, 520-524 (2005)

26. Derwenskus, K.H. \& Sprinzl, M. Interaction of cinnamyl-tRNA ${ }^{\text {Phe }}$ with Escherichia coli elongation factor Tu. FEBS Lett. 151, 143-147 (1983).

27. Moazed, D. \& Noller, H.F. Intermediate states in the movement of transfer RNA in the ribosome. Nature 342, 142-148 (1989).

28. Bevilacqua, P.C. Mechanistic considerations for general acid-base catalysis by RNA: revisiting the mechanism of the hairpin ribozyme. Biochemistry 42, 2259-2265 (2003).

29. Fedor, M.J. \& Williamson, J.R. The catalytic diversity of RNAs. Nat. Rev. Mol. Cell Biol. 6, 399-412 (2005).

30. Okuda, K., Seila, A.C. \& Strobel, S.A. Uncovering the enzymatic $\mathrm{pK}_{\mathrm{a}}$ of the ribosomal peptidyl transferase reaction utilizing a fluorinated puromycin derivative. Biochemistry 44, 6675-6684 (2005).
31. Muth, G.W., Ortoleva-Donnelly, L. \& Strobel, S.A. A single adenosine with a neutral pKa in the ribosomal peptidyl transferase center. Science 289, 947-950 (2000).

32. Xiong, L., Polacek, N., Sander, P., Bottger, E.C. \& Mankin, A. pKa of adenine 2451 in the ribosomal peptidyl transferase center remains elusive. RNA 7, 1365-1369 (2001).

33. Bayfield, M.A., Dahlberg, A.E., Schulmeister, U., Dorner, S. \& Barta, A. A conformational change in the ribosomal peptidyl transferase center upon active/inactive transition. Proc. Natl. Acad. Sci. USA 98, 10096-10101 (2001).

34. Brunelle, J.L., Youngman, E.M., Sharma, D. \& Green, R. The interaction between C75 of tRNA and the A loop of the ribosome stimulates peptidyl transferase activity. RNA 12, 33-39 (2006)

35. Hesslein, $A . E$ et al. Exploration of the conserved $A+C$ wobble pair within the ribosomal peptidyl transferase center using affinity purified mutant ribosomes. Nucleic Acids Res. 32, 3760-3770 (2004).

36. Beringer, M. et al. Essential mechanisms in the catalysis of peptide bond formation on the ribosome. J. Biol. Chem. 280, 36065-36072 (2005).

37. Weinger, J.S., Parnell, K.M., Dorner, S., Green, R. \& Strobel, S.A. Substrate-assisted catalysis of peptide bond formation by the ribosome. Nat. Struct. Mol. Biol. 11, 1101-1106 (2004).

38. Das, G.K., Bhattacharyya, D. \& Burma, D.P. A possible mechanism of peptide bond formation on ribosome without mediation of peptidyl transferase. J. Theor. Biol. 200, 193-205 (1999).

39. Radzicka, A. \& Wolfenden, R. A proficient enzyme. Science 267, 90-93 (1995).

40. Rodnina, M.V. \& Wintermeyer, W. Fidelity of aminoacyl-tRNA selection on the ribosome: kinetic and structural mechanisms. Annu. Rev. Biochem. 70, 415-435 (2001).

41. Rodnina, M.V. \& Wintermeyer, W. GTP consumption of elongation factor Tu during translation of heteropolymeric mRNAs. Proc. Natl. Acad. Sci. USA 92, 1945-1949 (1995).

42. Rodnina, M.V. et al. Thiostrepton inhibits turnover but not GTP hydrolysis by elongation factor G on the ribosome. Proc. Natl. Acad. Sci. USA 96, 9586-9590 (1999).

43. Johnson, A.E., Adkins, H.J., Matthews, E.A. \& Cantor, C.R. Distance moved by transfer RNA during translocation from the A site to the $\mathrm{P}$ site on the ribosome. J. Mol. Biol. 156, 113-140 (1982)

44. Fahnestock, S., Neumann, H. \& Rich, A. Assay of ester and polyester formation by the ribosomal peptidyltransferase. Methods Enzymol. 30, 489-497 (1974).

45. Stern, S., Moazed, D. \& Noller, H.F. Structural analysis of RNA using chemical and enzymatic probing monitored by primer extension. Methods Enzymol. 164, 481-489 (1988). 